\title{
Respostas esperadas de seleção para coloração de fritura em quatro populações híbridas de batata
}

\author{
Laerte R Terres$^{1}$; Vicenti G Ney ${ }^{1}$; Murilo de F Cerioli ${ }^{1}$; Arione da S Pereira² ${ }^{2}$ Rosa de O Treptow ${ }^{2}$ \\ 1UFPel-FAEM, C. Postal 354, 96010-900 Pelotas-RS; laerte_terres@yahoo.com.br; vicentig@gmail.com; murilo.cerioli@hotmail.com; \\ ${ }^{2}$ Embrapa Clima Temperado, C. Postal 403,96010-971 Pelotas-RS; arione.pereira@cpact.embrapa.br; rotreptow@hotmail.com
}

\section{RESUMO}

O objetivo deste estudo foi investigar a resposta esperada de seleção para coloração de fritura, bem como suas correlações com caracteres agronômicos, em quatro populações híbridas de batata. Os trabalhos foram realizados no campo experimental e no laboratório da Embrapa Clima Temperado, nas safras de outono de 2007 e 2008. As quatro populações foram derivadas de cruzamentos entre genitores com diferentes níveis de açúcares redutores (AR). Foram avaliadas a coloração de fritura na forma de chips, o ciclo de desenvolvimento das plantas, a massa de tubérculos, o número de tubérculos, a massa média de tubérculos e a aparência de tubérculos. Os dados foram analisados estatisticamente segundo modelo (Maximum Restricted Likelihood/ Best Linear Unbiased Prediction) REML/BLUP, de modo que distinguissem os efeitos fixos e os aleatórios. As populações não apresentaram diferenças significativas de respostas esperadas de seleção, apesar de diferirem em estimativa de valor genético e de herdabilidade. Maiores ganhos de seleção para coloração de chips poderiam ser esperados somente como resultados das menores médias (coloração mais clara) das populações que não envolveram genitor com alto AR nas suas gerações. Coloração de chips foi fracamente correlacionado com caracteres agronômicos.

Palavras-chave: Solanum tuberosum, avanço genético, herdabilidade, valor genético, qualidade de processamento, açúcares redutores.

\begin{abstract}
Expected response to selection for frying color in four hybrid potato populations

The objective of this study was to investigate the expected response to selection for chip color, and its correlations with some horticultural traits, in four hybrid potato populations. The work was carried out on the experimental field and the laboratory of Embrapa Temperate Agriculture, Pelotas, Rio Grande do Sul State, Brazil, in the autumn seasons of 2007 and 2008. The four populations were derived from crossing genitors with different levels of reducing sugars (AR). The chip color, plant development cycle, tuber yield, number of tubers, average tuber weight and tuber appearance were evaluated. Data were statistically analyzed according to the REML/BLUP model, in a way to distinguish fixed and random effects. The populations did not show significant differences in expected response to selection for chip color, despite differing in genetic value and heritability estimates. Higher genetic gains for chip color could be expected only as result of the lower means (lighter color) of the populations that did not include high AR parent in their generation.
\end{abstract}

Keywords: Solanum tuberosum, genetic advance, heritability, genetic value, processing quality, reducing sugars.

\section{(Recebido para publicação em 30 de janeiro de 2012; aceito em 23 de maio de 2012) (Received on January 30, 2012; accepted on May, 23 2012)}

$\mathrm{O}_{\mathrm{b}}^{\mathrm{s}}$ produtos industrializados de batata têm alcançado um desenvolvimento importante e uma rápida diversificação, como na forma de chips e batata palha, ou prontos para serem preparados, como batatas descascadas ou cortadas em palitos resfriados e pré-fritas congeladas (Geraldini et al., 2011). Entretanto, existe uma grande carência de cultivares com características que atendam plenamente os requisitos da indústria e a adaptação à produção no Brasil (Pereira \& Daniels, 2003). Para que uma cultivar de batata seja aceita pelo mercado de processamento na forma de palitos ou chips, precisa principalmente que a coloração do produto final seja clara (Pereira et al., 2007).

$\mathrm{O}$ escurecimento dos chips e palitos fritos é devido à reação de açúcares redutores com proteínas e aminoácidos livres que ocorre durante a fritura, reação de Maillard (Feltran et al., 2004). Há uma forte e positiva associação entre a coloração do produto frito e o teor de açúcares redutores nos tubérculos (Menéndes et al., 2002; MacCann et al., 2010), caráter limitante na seleção de clones de batata para processamento industrial (Souza et al., 2011). Em batatas para processamento, o teor de açúcares redutores geralmente aceito é abaixo de $0,035 \%$ da massa fresca para chips e $0,12 \%$ para palitos (Stark et al., 2003).

A coloração de chips é influenciada por fatores genéticos e ambientais (Pastorini et al., 2003). O valor fenotípico do indivíduo pode ser medido diretamente, mas é o valor genético que determina a sua influência na geração seguinte (Falconer, 1989). Portanto, a escolha de indivíduos, de acordo com seus valores fenotípicos, depende do sucesso das alterações das características da população, que pode ser predito somente por intermédio do conhecimento do grau de correspondência entre o valor fenotípico e o valor genético.

A herdabilidade de um caráter depende dos componentes da variância, qualquer alteração em um deles influencia o valor da proporção herdável. É o grau em que o fenótipo é influenciado geneticamente, portanto, o grau em que ele pode ser modificado pela seleção fenotípica (Carvalho et al., 2001).

Para definir estratégias eficientes de 
seleção, é necessário dispor de informações de genética quantitativa em relação às populações a serem utilizadas, sobre a extensão da variância genética, herdabilidade, correlação entre caracteres e predição de resposta de seleção (Nguyen \& Sleper, 1983).

Neste contexto, este estudo objetivou investigar a resposta esperada de seleção para coloração de chips, bem como suas correlações com caracteres agronômicos, em quatro populações híbridas de batata.

\section{MATERIAL E MÉTODOS}

Foram avaliadas quatro populações híbridas de batata derivadas de cruzamentos entre clones com diferentes níveis de açúcares redutores (AR): população C-2504, obtida do cruzamento C-1750-15-95/C-1883-22-97 (médio AR / baixo AR); população C-2509, derivada do cruzamento BR-3/C-1890-1-97 (alto AR / médio-alto AR); população C-2524, produzida do cruzamento C-1786-6-96/C-1883-22-97 (médio-baixo AR / baixo AR); população C-2530, derivada do cruzamento C-1750-15-95/C-1890-1-97 (médio AR / médio-alto AR). Além dos genitores, foram incluídos como testemunhas os seguintes genótipos: Agata (alto AR), Atlantic (baixo AR), Monte Bonito (médio-alto AR), 2CRI-1149-1-78 (médio-alto AR) e C-1714-7-94 (médio AR), representando a amplitude de coloração de chips.

Os trabalhos foram realizados no campo experimental e no da Embrapa Clima Temperado, Pelotas-RS (31 ${ }^{\circ} 52^{\prime} \mathrm{S}$, $\left.52^{\circ} 21^{\prime} \mathrm{W}\right)$, nas safras de outono de 2007 e 2008. O delineamento experimental foi blocos aumentados de Federer \& Raghavarao (1955), com quatro repetições das testemunhas. Em 2007, a parcela foi constituída por três plantas de cada clone, enquanto em 2008, consistiu de cinco plantas. O solo onde foram conduzidos os experimentos é classificado como Argissolo Vermelho Amarelo Distrófico Típico, e foi adubado nos sulcos de plantio com 2.000 $\mathrm{kg} \mathrm{ha}^{-1}$ de NPK (5-30-10). Os plantios dos experimentos foram realizados em 11 de março de 2007 e 20 de março de 2008, com espaçamento de $30 \mathrm{~cm}$ entre plantas e de $80 \mathrm{~cm}$ entre linhas. O controle de doenças e outras práticas foram uniformes e semelhantes às usadas nos plantios comerciais da região. As plantas foram mantidas em campo até completarem o ciclo de desenvolvimento, quando os tubérculos foram colhidos em 24 de junho de 2007 e 5 de julho de 2008, e transportados para instalações apropriadas, onde foram efetuadas as avaliações.

Amostras de três tubérculos sadios de cada parcela, classificados como comerciais (diâmetro $>45 \mathrm{~mm}$ ), foram utilizadas para avaliação da coloração de fritura. Os tubérculos foram descascados e fatiados na forma de chips a uma espessura de $2 \mathrm{~mm}$. Doze fatias foram fritas em uma fritadeira elétrica (marca Tedesco), utilizando gordura hidrogenada à temperatura inicial de $180^{\circ} \mathrm{C}$ até cessar a borbulha. A coloração dos chips foi avaliada, atribuindo notas visualmente, por avaliadores treinados, comparando com a escala da Potato Chip and Snack Food Association (Douches, 1996), adaptada para nove pontos: $1=$ coloração clara, $9=$ coloração escura. Foram considerados como aceitável para processamento os clones com chips de nota 2 ou inferior.

No experimento de 2008, adicionalmente à avaliação da coloração de chips, os clones foram avaliados quanto ao ciclo de desenvolvimento das plantas, segundo o grau de senescência ( $1=$ tardia; 9= precoce), massa de tubérculos $\left(\mathrm{kg} \mathrm{parcela}^{-1}\right)$, número de tubérculos por parcela, massa média de tubérculos e aparência de tubérculos ( $1=$ excelente; $9=$ péssimo). A massa média de tubérculos foi obtida por meio da razão entre a massa e o número de tubérculos. A aparência de tubérculos foi considerada excelente naqueles que apresentaram tubérculos atrativos, com uma coloração amarela clara ou vermelha "viva", película lisa, brilhante, formato alongado e uniforme, olhos rasos e tamanho médio a grande (Pereira \& Daniels, 2003).

Os dados foram analisados por meio dos programas computacionais GENES (Cruz, 2006) e SAS Learning Edition (2002). O programa GENES foi utilizado para análise de variância, comparação de médias, segundo o teste de Tukey, e análise de correlação entre caracteres.
O programa SAS Learning Edition (2002) foi aplicado, utilizando o procedimento Proc Mixed, apropriado para a análise de modelos mistos desbalanceados, pois distingue claramente os efeitos fixos e os aleatórios (Littell et al., 1996). O modelo estatístico usado para a determinação dos efeitos genéticos, desconsiderando o efeito ambiental, foi REML/BLUP (máxima verossimilhança restrita/melhor estimativa linear não-viesada). Matricialmente, o modelo misto linear geral (Harville, 1977) é definido como:

$$
\mathrm{y}=\mathrm{X} \beta+\mathrm{Zv}+\mathrm{e}
$$

em que: ${ }_{\mathrm{n}} \mathrm{y}$ l é o vetor de observações; ${ }_{n} \mathrm{X}_{\mathrm{p}+1}$ é a matriz de incidência dos efeitos fixos (conhecida); ${ }_{p+1} \beta 1$ é o vetor de efeitos fixos desconhecidos; ${ }_{n} Z_{\mathrm{q}}$ é a matriz de incidência dos efeitos aleatórios (conhecida); $v 1$ é o vetor de efeitos aleatórios desconhecidos; $\mathrm{n}$ el é o vetor de erros aleatórios; sendo, n o número de observações, $\mathrm{p}$, o número de parâmetros e q o números de efeitos aleatórios.

A herdabilidade e a resposta esperada de seleção para coloração de chips foram estimadas segundo Simmonds (1979), calculado pela média dos valores genéticos dos clones selecionados e a intensidade de seleção de $10 \%$.

\section{RESULTADOS E DISCUSSÃO}

A análise da variância revelou diferenças significativas $(\mathrm{p}<0,05)$ entre as populações híbridas de batata quanto à coloração de chips (dados não apresentados). A interação ano de cultivo $\mathrm{x}$ populações não foi significativa.

As médias de coloração de chips foram mais baixas, isto é, mais claras nas populações C-2504 (médio de açúcares redutores (AR)/baixo teor de açúcares redutores), C-2524 (médio-baixo $\mathrm{AR} /$ baixo AR) e C-2530 (médio AR/médio-alto AR) que na população C-2509 (alto AR/médio AR) (Tabela 1). 'C-2509' foi a única das quatro populações que foi derivada de cruzamento, envolvendo um genitor com alto AR. Por outro lado, os dados de amplitude mostram que todas as quatro populações incluíram indivíduos com chips de coloração clara (nota igual ou menor que 2). 
Tabela 1. Médias e amplitudes de coloração de chips ${ }^{1}$ de quatro populações híbridas de batata cultivadas nas safras de outono de 2007 e 2008 (means and range for chip color of four hybrid potato populations grown in autumn seasons of 2007 and 2008). Pelotas, Embrapa Clima Temperado, 2009.

\begin{tabular}{|c|c|c|c|c|c|}
\hline \multirow{2}{*}{ População } & \multirow{2}{*}{ Cruzamento } & \multicolumn{2}{|c|}{2007} & \multicolumn{2}{|c|}{2008} \\
\hline & & Média & Amplitude & Média & Amplitude \\
\hline C-2530 & C-1750-15-95/C-1890-1-97 & $4,46 b^{2}$ & $1,0-8,0$ & $2,88 \mathrm{~b}$ & $1,0-6,0$ \\
\hline C-2524 & C-1786-6-96/C-1883-22-97 & $4,52 \mathrm{~b}$ & $1,0-8,0$ & $2,61 \mathrm{~b}$ & $1,0-6,0$ \\
\hline C-2504 & C-1750-15-95/C-1883-22-97 & $5,35 \mathrm{~b}$ & $2,0-8,0$ & $2,56 \mathrm{~b}$ & $1,0-7,0$ \\
\hline C-2509 & BR-3/C-1890-1-97 & $6,77 \mathrm{a}$ & $2,0-9,0$ & $5,25 \mathrm{a}$ & $1,0-8,0$ \\
\hline
\end{tabular}

${ }^{1}$ Coloração de chips: $1=$ coloração clara, $9=$ coloração escura (chip color: $1=$ light color, $9=$ dark color); ${ }^{2}$ Médias seguidas de letras distintas na coluna diferem entre si a $5 \%$ de probabilidade do erro pelo teste de Tukey (means followed by different letters in the column differ among themselves at $5 \%$ error probability by the Tukey test).

Tabela 2. Estimativas do valor genético (BLUP), herdabilidade $\left(\mathrm{h}^{2}\right)$, resposta esperada de seleção (R) e seus limites inferior e superior, calculados a partir dos valores genéticos para coloração de chips de tubérculos de batata, nas safras de outono de 2007 e 2008 [estimates of genetic value (BLUP), heritability $\left(\mathrm{h}^{2}\right)$, expected response to selection (R) and their upper and lower limits, calculated from the genetic values for chip color of potato tubers, in autumn seasons of 2007 and 2008]. Pelotas, Embrapa Clima Temperado, 2009.

\begin{tabular}{|c|c|c|c|c|c|c|c|c|c|}
\hline \multirow{3}{*}{$\begin{array}{l}\text { População } \\
\text { (cruzamento) }\end{array}$} & \multicolumn{3}{|c|}{ BLUP } & \multicolumn{3}{|c|}{$\mathbf{h}^{2}$} & \multicolumn{3}{|c|}{$\mathbf{R}$} \\
\hline & \multirow{2}{*}{$\begin{array}{l}\text { Valor } \\
\text { médio }\end{array}$} & \multicolumn{2}{|c|}{ Limite } & \multirow{2}{*}{$\begin{array}{l}\text { Valor } \\
\text { médio }\end{array}$} & \multicolumn{2}{|c|}{ Limite } & \multirow{2}{*}{$\begin{array}{l}\text { Valor } \\
\text { médio }\end{array}$} & \multicolumn{2}{|c|}{ Limite } \\
\hline & & Inferior & Superior & & Inferior & Superior & & Inferior & Superior \\
\hline $\begin{array}{l}\mathrm{C}-2524 \\
(\mathrm{C}-1786-6-96 / \mathrm{C}-1822-22-97)\end{array}$ & $-0,70$ & $-1,86$ & 0,45 & 0,42 & 0,31 & 0,53 & $-92,75$ & $-246,45$ & 64,20 \\
\hline $\begin{array}{l}\text { C-2530 } \\
(C-1750-15-95 / C-1890-1-97)\end{array}$ & $-0,61$ & $-1,77$ & 0,54 & 0,35 & 0,24 & 0,46 & $-80,82$ & $-234,52$ & 71,55 \\
\hline $\begin{array}{l}\text { C-2504 } \\
(\mathrm{C}-1750-15-95 / \mathrm{C}-1883-22-97)\end{array}$ & $-0,32$ & $-1,47$ & 0,83 & 0,18 & 0,07 & 0,29 & $-42,40$ & $-194,77$ & 109,97 \\
\hline $\begin{array}{l}\text { C-2509 } \\
(B R-3 / C-1890-1-97)\end{array}$ & 1,64 & 0,48 & 2,79 & 0,87 & 0,76 & 0,98 & 217,30 & 63,60 & 369,67 \\
\hline
\end{tabular}

Tabela 3. Coeficientes de correlação entre coloração de chips (COL), aparência de tubérculo (APA), ciclo de desenvolvimento das plantas (CIC), massa de tubérculo (MT), número de tubérculos (NT) e massa média de tubérculos de batata (MMT) [correlation coefficients between chip color (COL), tuber appearance (APA), cycle of plant development (CIC), tuber yield (MT), number of tubers (NT) and average tuber weight (MMT)]. Pelotas, Embrapa Clima Temperado, 2009.

\begin{tabular}{lccccc}
\hline Carater & APA & CIC & MT & NT & MMT \\
\hline APA & - & & & & \\
CIC & 0,02 & - & & & \\
MT & $0,17^{*}$ & $-0,02$ & - & & \\
NT & $-0,24^{*}$ & $-0,06$ & $0,29^{*}$ & - & \\
MMT & $0,27^{*}$ & $-0,14$ & $0,51^{*}$ & $-0,58^{*}$ & - \\
COL & 0,14 & 0,08 & $0,19^{*}$ & 0,00 & 0,08 \\
\hline
\end{tabular}

* Significativo a $5 \%$ de probabilidade de erro pelo teste $\mathrm{t}$ (significant at $5 \%$ probability of error by the $\mathrm{t}$ test).

Os valores genéticos médios das populações C-2524, C-2530 e C-2504 foram negativos, favorecendo a coloração mais clara de chips, enquanto da população C-2509 foi positivo, contribuindo para coloração escura de chips
(Tabela 2). No entanto, o valor genético da população C-2524 foi significativamente superior somente da população C-2509, não diferindo das populações C-2530 e C-2504, nem estas da população C-2509.
A herdabilidade estimada para a população $\mathrm{C}-2509$ foi alta $(\mathrm{h}=0,87) \mathrm{e}$ significativamente maior que para as outras três populações, superando estimativa encontrada por Haynes (2008) em estudo com três ciclos de seleção com híbridos diplóides. Para as populações C-2524 e C-2530, as herdabilidade foram de magnitude moderada $(\mathrm{h}=0,42$ $\mathrm{e} \mathrm{h}=0,35$, respectivamente), enquanto para a população C-2504 a estimativa foi baixa $(h=0,18)$, mas não diferiu significativamente da estimativa para população C-2530. Herdabilidades de magnitude moderada para coloração de chips também foram relatadas por outros autores (Thill \& Peloquin, 1994; Salamoni et al., 2000; Rodrigues \& Pereira, 2003).

A herdabilidade depende da diversidade genética do material em estudo e dos fatores ambientais (Falconer, 1989). Por conta disso, a população C-2509, que é originária de cruzamento entre um 
genitor com baixo AR e outro de elevado AR, apresentou a maior estimativa de herdabilidade, enquanto a população C-2504, que foi derivada do cruzamento entre genitores com médio AR e baixo AR, apresentou a estimativa de menor magnitude.

A resposta esperada de seleção serve de indicativo para a escolha de população a ser utilizada no desenvolvimento de cultivares (Allard, 1960). A média de resposta esperada de seleção para população C-2509 foi a mais elevada, mas não diferiu significativamente das outras três populações (Tabela 2).

O progresso esperado com a seleção depende da herdabilidade do caráter, da intensidade de seleção e do desvio padrão fenotípico do caráter (Dudley \& Moll, 1969; Simmonds, 1979). Embora a herdabilidade estimada para a população C-2509 tenha sido superior às estimativas para as demais populações, não foi suficiente para resultar em resposta esperada de seleção significativamente mais elevada.

Os resultados encontrados neste estudo sugerem que maiores ganhos de seleção para coloração de chips poderiam ser esperados somente como produto da menor média (coloração mais clara) das populações que não envolveram genitor com alto AR nas suas gerações.

Quanto às correlações entre coloração de chips e caracteres componentes de produção e ciclo de desenvolvimento das plantas, apenas a correlação entre coloração de chips e massa de tubérculos foi significativa, porém de baixa magnitude (Tabela 3). Este resultado confirma os níveis de correlação entre coloração de chips e caracteres de produção relatados anteriormente (Rodrigues \& Pereira, 2003; Augustin, 2007). Os coeficientes de correlação entre coloração de chips e número de tubérculos, massa média de tubérculos, aparência de tubérculos e ciclo de desenvolvimento das plantas foram baixos e não significativas. $\mathrm{O}$ ciclo de desenvolvimento das plantas não se correlacionou com nenhum dos outros caracteres, enquanto aparência de tubérculos esteve fracamente correlacionada com caracteres de produção.

Os resultados deste estudo permitem concluir que a herdabilidade do caráter coloração de chips varia de baixa a alta, dependendo do nível de açúcares redutores dos genitores envolvidos na geração da população; as respostas esperadas de seleção para coloração de chips não diferem entre populações derivadas de cruzamentos entre genitores com médio AR/baixo AR, médio-baixo AR/ baixo $A R$, médio $A R /$ médio-alto $A R$ e alto AR/médio AR; ganhos maiores de seleção para coloração de chips podem ser esperados somente como produto da menor média (chips mais claros) das populações que não envolvem genitor com alto AR; e coloração de chips é fracamente correlacionada com caracteres agronômicos.

\section{AGRADECIMENTOS}

Os autores agradecem a CAPES e ao CNPq pelas bolsas concedidas e suporte financeiro.

\section{REFERÊNCIAS}

ALLARD RW. 1960. Principles of plant breeding. New York: Wiley. 485p.

AUGUSTIN L. 2007. Interação genótipo $x$ ambiente e variabilidade genética de caracteres agronomicos e qualidade de processamento de batata. Passo Fundo: UPF. 132p. (Tese doutorado)

CARVALHO FIF; SILVA AS; KUREK AJ; MARCHIORO VS. 2001. Estimativas e implicações da herdabilidade como estratégia de seleção. Pelotas: Editora Universitária da UFPel. 91p.

CRUZ CD. 2006. Programa Genes: Biometria. Viçosa: Editora UFV. 382p.

DOUCHES DS. 1996. Assessment of potato breeding progress in the USA over the last century. Crop Science 36: 1544-1552.

DUDLEY JW; MOLL RH. 1969. Interpretation and use of estimation of heritability and genetic variance in plant breeding. Crop Science 2: 257-262.

FALCONER DS. 1989. Introduction to quantitative genetics. 3rd ed. New York: Longman. 438p.

FEDERER WT; RAGHAVARAO D. 1955. On augmented designs. Biometrics 31: 29-35.

FELTRAN JC; BORGES LL; VIEITES RL. 2004. Technological quality and utilization of potato tubers. Scientia Agricola 61: 598-603.

GERALDINI F; JULIÃO L; BROGATO E. 2011. Procuram-se agroindústrias. Hortifruti Brasil 10: 8-23.

HARVILLE DA. 1977. Maximum-likelihood approaches to variances component estimation and to related problems. Journal of the American Statistical Association 72: 320-340.

HAYNES KG. 2008. Heritability of chip color and specific gravity in a long-day adapted Solanum phureja-S. stenotomum population. American Journal of Potato Research 85:361-366.

LITTELL RC; MILLIKEN GA; STROUP WW; WOLFINGER RD. 1996. SAS system for mixed models. Cary: Statistical Analysis System Institute. 633p.

MCCANN LC; BETHKE PC; SIMON PW. 2010. Extensive variation in fried chip color and tuber composition in cold-stored tubers of wild potato (Solanum) germplasm. Journal of Agricultural and Food Chemistry 58: 2368-2376.

MENÉNDES CM; RITTER E; SCHÂFERPREGL R. 2002. Cold sweetening on diploid potato: Mapping quantitative trait loci and candidate genes. Genetics 162: 1425-1434.

NGUYEN HT; SLEPER DA. 1983. Theory and application of half-sib matings in forage breeding. Theoretical and Applied Genetics 64: 187-196.

PASTORINI LH; BACARIN MA; TREVIZOL FC; BERVALD CMP; FERNANDES HS. 2003. Produção e teor de carboidratos não estruturais em tubérculos de batata obtidos em duas épocas de plantio. Horticultura Brasileira 21: 660-665.

PEREIRA AS; DANIELS J. 2003. O cultivo da batata na região sul do Brasil. Brasília: Embrapa Informação Tecnológica/Embrapa Clima Temperado. $567 \mathrm{p}$.

PEREIRA AS; NETO RF; SILVA RS. 2007. Genótipos de batata com baixo teor de açúcares redutores. Horticultura Brasileira 25: 220-223.

RODRIGUES AFS; PEREIRA AS. 2003. Correlações inter e intragerações e herdabilidade de cor de chips, matéria seca e produção em batata. Pesquisa Agropecuária Brasileira 38: 599-604.

SALAMONI AT; PEREIRA AS; VIÉGAS J; CAMPOS AD; CHALÁ CSA. 2000. Variância genética de açúcares redutores e matéria seca e suas correlações com características agronômicas. Pesquisa Agropecuária Brasileira 35: 1441-1445.

SAS LEARNING EDITON. 2002. Getting Started with the SAS Learning Edition. Cary: SAS Institute. $81 \mathrm{p}$.

SIMMONDS NW. 1979. Principles of crop improvement. New York: Longman. 408p.

SOUZA ZS; BISOGNIN DA; MORIN JUNIOR GR; GNOCATO FC. 2011. Seleção de clones de batata para processamento industrial em condições de clima subtropical e temperado. Pesquisa Agropecuária Brasileira 46: $1503-$ 1512.

STARK JC; OLSEN N; KLEINKOPF GE; LOVE SL. 2003. Tuber quality. In: STARK JC; LOVE SL (eds). Potato production systems. Aberdeen: University of Idaho. p. 329-343.

THILL CA; PELOQUIN SJ. 1994. Inheritance of potato chip color at the 24 chromosome level. American Potato Journal 71: 629-646. 